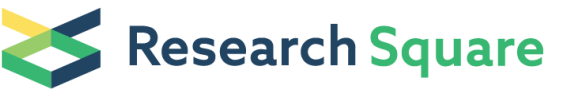

Preprints are preliminary reports that have not undergone peer review. They should not be considered conclusive, used to inform clinical practice, or referenced by the media as validated information.

\section{Total Hip Arthroplasty After Failed Less Invasive Hip Preservation Surgery for Osteonecrosis of the Femoral Head: A Systematic Review and Meta-analysis}

\section{liang mo}

Guangzhou University of Traditional Chinese Medicine: Guangzhou University of Chinese Medicine

\section{Jianxiong Li}

Guangzhou University of Traditional Chinese Medicine: Guangzhou University of Chinese Medicine

\section{Zhangzheng Wang}

Guangzhou University of Traditional Chinese Medicine: Guangzhou University of Chinese Medicine

\section{Fayi Huang}

Guangzhou University of Traditional Chinese Medicine: Guangzhou University of Chinese Medicine

\section{Pengfei Xin}

Guangzhou University of Traditional Chinese Medicine: Guangzhou University of Chinese Medicine

\section{Chao Ma}

Guangzhou University of Traditional Chinese Medicine: Guangzhou University of Chinese Medicine Jiahao Zhang

Guangzhou University of Traditional Chinese Medicine: Guangzhou University of Chinese Medicine

\section{Haoran Huang}

Guangzhou University of Traditional Chinese Medicine: Guangzhou University of Chinese Medicine

\section{Chi Zhou}

Guangzhou University of Traditional Chinese Medicine: Guangzhou University of Chinese Medicine

Yuhao Liu ( $\nabla$ doctor_yuhaoliu@126.com )

Guangzhou University of Traditional Chinese Medicine: Guangzhou University of Chinese Medicine

\section{Wei He}

Guangzhou University of Traditional Chinese Medicine: Guangzhou University of Chinese Medicine

\section{Research Article}

Keywords: total hip arthroplasty, osteonecrosis of the femoral head, hip preservation surgery, meta-analysis

Posted Date: November 19th, 2021

DOI: https://doi.org/10.21203/rs.3.rs-1079335/v1

License: (c) (i) This work is licensed under a Creative Commons Attribution 4.0 International License. Read Full License 


\section{Abstract}

\section{Background}

Less invasive hip-preserving surgery (LIHP) is an effective treatment in delaying total hip arthroplasty (THA) for young patients with osteonecrosis of the femoral head (ONFH). But the success rate of it was not as effective as expected and were significantly reduced with the advancement of the diseases stages. Therefore, it is essential to analysis the impact of LIHP on subsequent THA.

Methods

The search language was restricted to Chinese and English, and the references of included studies were also searched. Chinese databases including CNKI, Wan-Fang databases and VIP, and English databases including PubMed, Embase and Cochrane library were searched by the computer from the inception of each database to 23rd May 2021. The outcome indicators were extracted from the included literature and analyzed by Cochrane Collaboration Review Manager software (RevMan version 5.4). The quality of the studies was scored using the Newcastle-Ottawa scale (NOS).

Results

A total of nine articles met the inclusion and were included in this meta-analysis, two of them were published in Chinese and the remaining studies were published in English. Results showed that the LIHP group has longer operative time ( $\mathrm{SMD}=17.31,95 \% \mathrm{Cl}=6.29$ to $28.32, p=0.002)$, more intraoperative blood loss ( $\mathrm{SMD}=79.90$, $95 \% \mathrm{Cl}=13.92$ to $145.87, p=0.02)$ and higher rate of varus or valgus femoral stem $(\mathrm{OR}=4.17,95 \% \mathrm{Cl}=1.18$ to $14.71, p=0.03)$ compared to primary THA group. The risk of intraoperative fracture was higher in the prior LIHP THA group compared with primary THA group but the difference was not statistically significant $(O R=5.88$, $95 \% \mathrm{Cl}=0.93$ to $37.05, p=0.06$ ). While there was no significant difference in cup anteversion angle $(S M D=-0.10$, $95 \% \mathrm{Cl}=-0.61$ to $0.41, p=0.70)$, cup inclination angle $(\mathrm{SMD}=0.58,95 \% \mathrm{Cl}=-0.05$ to $1.22, p=0.07)$, postoperative Harris Hip Score (HHS) (SMD $=-0.01,95 \% \mathrm{Cl}=-0.43$ to $0.46, p=0.96)$ and survivorship $(\mathrm{OR}=1.38,95 \% \mathrm{Cl}=0.34$ to $5.55, p=0.65$ ) between THA groups with and without prior LIHP.

\section{Conclusion}

Although the prior LIHP increased the difficulty of the conversion to THA with longer operative time, more intraoperative blood loss, and higher rate of intraoperative fracture, it does not detrimentally affect the clinical results of subsequent THA in the mid-term following-up.

\section{Introduction}

Osteonecrosis of the femoral head (ONFH) is a progressive disabling and refractory bone joint disease that mainly affects young and middle-aged adults[1]. It is a male-dominant disease, with the incidence of ONFH 3fold higher in males than in females and bilateral hip involvement is common (approximately 75\%)[2]. According to epidemiological reports, the incidence rate of ONFH has been increasing worldwide, and the unreasonable and excessive steroid use has exacerbated the trend of young age $[3,4]$. The pathogenesis of ONFH has yet to be fully clarified, and the treatments are mainly toward providing symptomatic management[5]. 
Total hip arthroplasty (THA) is the most common surgical procedure for patients with ONFH[6]. However, THA is not an ideal choice for young patients because they will face the risk of revision in the future, and the risk of failure in such operations is high due to the loss of bone mass[7]. Hence, hip-preserving surgery has important clinical and social value in the treatment of young patients with $\mathrm{ONFH}[8]$.

Hip-preserving surgery should slow or even prevent the progress of the collapse of the femoral head, so as to delay THA as much as possible. Now, the methods of hip preserving operation in clinical, such as core decompression, non-vascularized or vascularized bone-grafting, and tantalum rod implantation, have achieved a certain effect [9-11]. But the success rate of hip-preserving surgical treatments listed above was not as effective as expected and were significantly reduced with the advancement of the diseases stages[8, 11-13]. In a metaanalysis of core decompression with insertion of a tantalum rod in the treatment of ONFH, at a mean follow-up of 26.97 months, $24.63 \%$ of the included hips underwent a hip arthroplasty[14]. THA is currently recognized as an end-stage treatment for hip joint disease, so for patients who receive THA following failed hip-preserving surgery, we have to considerate that whether or not prior hip-preserving surgery has detrimental effect on subsequent THA for ONFH.

Generally speaking, different hip-preserving procedures have shown different effects on the subsequent THA. Some studies have shown that the techniques of hip-preserving could be subdivided into two main categories depending on the technical requirement and invasiveness of the procedure: the less invasive hip-preserving procedures (LIHP) including core decompression with or without any supporting structure and the more invasive hip-preserving procedures (MIHP) including rotational osteotomy or vascularized bone grafting[15, 16]. To our knowledge, earlier meta-analysis literatures stated that subsequent THA after the prior transtrochanteric rotational osteotomy and pelvic osteotomy had a comparable clinical result with primary THA[17, 18]. Wang et al[15] performed a systematic review and meta-analysis with respect to the effect of prior LIHP on subsequent THA for ONFH; while pooled analyses of several valuable outcome parameters were unavailable due to limited number of trials. Recently, some high-quality studies were published and for the purpose of better illustrating this issue, an update of the review is necessary.

In this study, a thorough search was conducted to retrieve trials of subsequent THA after LIHP. We will provide updated evidence on the surgical results (including operative time, operative blood loss, and complications) and clinical outcomes.

\section{Material And Methods}

\subsection{Search strategy}

The guidelines of the Preferred Reporting Items for Systematic Reviews and Meta-Analyses statement (PRISMA) were followed by this present study[19]. Approval or patient consent was not necessary because all the analyses were performed on the basis of previous published studies. The search language was restricted to Chinese and English, and the reference of the included studies were also searched. Chinese databases including CNKI, WanFang databases and VIP, and English databases including PubMed, Embase and Cochrane library were searched by computer from the inception of each database to 23rd May 2021. The following search terms were used: ('arthroplasty, replacement, hip' or 'total hip arthroplasty' or 'THA' or 'hip prosthesis implantation' or 'hip replacement arthroplasty'), and ('core decompression' or 'decompression' or 'bone grafting' or 'grafting, bone' or 
'tantalum implant' or 'tantalum rod implantation' or 'trabecular meta implant' or 'metal implant'). All identified articles were individually examined to check for inclusion. Taking the PubMed database as an example, the literature search strategy is shown in Table1.

\subsection{Eligibility criteria}

The literature was screened according to the following inclusion criteria:

i. study design included case-control and retrospective.

ii. less invasive hip-preserving procedures (LIHPs) included CD, non-vascularized autogenous bone graft or allograft, and tantalum rod.

In this study, we only included the less invasive hip-preserving procedures (LIHPs) including core decompression with or without any supporting structure. The more invasive hip-preserving procedures (MIHPs) including vascularised bone grafts and transtrochanteric rotational osteotomy were not included due to the significant invasiveness of the procedure. Duplicate publications and articles, reviews, letters, comments, and meeting proceedings were also excluded.

\subsection{Study selection and data extraction}

For the inclusion decision, two investigators independently evaluated the eligibility of studies. If they both agreed, the study would be included in this present study, and any inconsistencies were resolved with consensus of all investigators.

Design information, baseline population characteristics (age, sex, sample size and country), surgical procedure, body mass index, and follow-up period after the THA from all included studies were stratified into a standardized evidence table. Parameters of the outcomes for the meta-analysis, including operative time, operative blood loss, complications, radiological parameters, and clinical outcomes.

\subsection{Quality assessment}

Two independently reviewers evaluated the included studies based on the items of modified Newcastle-Ottawa Scale (NOS)[20], comprising patient selection, study group comparability and outcome assessment; six or more stars was considered to be a study of high quality.

\subsection{Statistical analysis}

The meta-analysis and statistical analysis were performed using Cochrane Collaboration Review Manager software (RevMan version 5.4), with $p \varangle 0.05$ set as the statistically significant threshold. For continuous data with standard deviation, meta-analysis was performed to calculate the weighted mean difference (WMD) with 95\% confidence intervals $(\mathrm{Cl})$. When comparing the incidence of dichotomous data, such as revision or complications, we calculated relative risk (RR) with a $95 \% \mathrm{Cl}$ for each outcome. Statistical heterogeneity was assessed based on $R^{2}$ using standard $c^{2}$ test. When $R^{2}>50 \%$, a high degree of heterogeneity was assumed and a random-effects model was applied. When $R^{2}<50 \%$, a low degree of heterogeneity was assumed and a fixedeffects model was applied. For studies that reported continuous variable with ranges without the standard 
deviation (SD), we conducted authors for additional information or estimated the SD using the Walter method[21]. Subgroup analysis was applied for the outcomes by grouping studies on the type of hip-preserving surgery. The subgroup can be broadly divided into two groups: tantalum rod implantation and non-tantalum rod implantation (including non-vascularized bone grafting or cementing).

\section{Results}

\subsection{Search results and characteristics}

A total of 2102 studies were identified by the search strategy. Of those articles, 565 studies were excluded because of duplication. Then, 1481 studies were excluded by title and abstract screening. Of the remaining 56 articles, 47 articles were excluded by reviewing the full text. A total of nine retrospective studies met inclusion criteria, and details of the study selection was shown in Fig1. Two of them[26,29] were published in Chinese and the remaining studies[16,22-25,27-28] were published in English. See Table2 and Table3 for detailed information of the included studies.

\subsection{Quality assessment}

Newcastle Ottawa Scale (NOS) was used to evaluate the eligibility of included studies, and high quality was assigned when NOS score was ${ }^{3} 7$. The 3 sections of the NOS (selection, comparability, and outcome) were used to score the included studies, and details are shown in Table3.

\subsection{Primary results of meta-analysis}

\subsubsection{Operative time}

Six articles $[16,23,25,27-29]$ reported about the data of operative time. The heterogeneity $\left(P^{2}=95 \%\right)$ was significant, therefore the random-effects model was used. After the quantitative analysis, operative time was longer in the prior LIHP group than the primary THA group ( $S M D=17.31,95 \% \mathrm{Cl}=6.29$ to $28.32, p=0.002)$. A subgroup analysis of five articles[23, 25, 27-29] showed that the difference in operative time between THA with a previous tantalum rod implanting and primary THA group was significant ( $\mathrm{SMD}=24.50,95 \% \mathrm{Cl}=14.09$ to $34.91, p$ $\nabla 0.00001)$. A subgroup analysis of two articles $[16,28]$ showed that the difference in operative time between THA with a previous bone grafting or cementing and control THA group was not significant (SMD $=-0.22,95 \% \mathrm{Cl}=-4.43$ to $3.98, p=0.92$ ). (Fig2)

\subsubsection{Intraoperative blood loss}

Five articles[16, 25, 27-29] reported about the intraoperative blood loss during the THA. There was significant heterogeneity $\left(R^{2}=95 \%\right)$, therefore the random-effects model was used. The pooled result indicated a trend toward more intraoperative blood loss in the prior LIHP THA group compared with control THA group $(\mathrm{SMD}=79.90,95 \% \mathrm{Cl}=13.92$ to $145.87, p=0.02)$. A subgroup analysis of four articles[25, 27-29] showed that there was significant difference in intraoperative blood loss between THA with a previous tantalum rod implanting and control THA group (SMD=114.74, 95\% $\mathrm{Cl}=33.52$ to $195.96, p=0.006)$. A subgroup analysis of two articles[16, 28] showed that there was significant difference in intraoperative blood loss between THA with a previous bone grafting or cementing and control THA group (SMD=-7.49, 95\%Cl=-51.09 to 36.11, $p=0.74)$. (Fig3) 


\subsubsection{Intraoperative fracture}

Three articles $[16,23,28]$ reported about the rate of intraoperative fracture. No heterogeneity $\left(I^{2}=0 \%\right)$ was observed, therefore the fixed-effects model was used. The summary estimate suggested that the risk of intraoperative fracture was higher in the prior LIHP THA group compared with control THA group but the difference was not statistically significant, either $(\mathrm{OR}=5.88,95 \% \mathrm{Cl}=0.93$ to $37.05, p=0.06)$. (Fig4a)

\subsubsection{Varus or valgus femoral stem}

Three articles[16, 26, 29] provided data to calculate OR and associated $95 \% \mathrm{Cl}$ of the varus or valgus femoral stem rate between two groups. The fixed-effects model was used for no significant heterogeneity $\left(R^{2}=0 \%\right)$. Result showed that the rate of varus or valgus femoral stem in the prior LIHP THA group was significantly higher compared with the control THA group (OR=4.17, 95\% Cl=1.18 to $14.71, p=0.03)$. (Fig4b)

\subsubsection{Cup anteversion angle}

Five articles[23, 25, 27-29] provided enough data to assess the cup anteversion angle in two groups. The fixedeffects model was used for no significant heterogeneity $\left(I^{2}=0 \%\right)$. Pooling the data showed that there was no significant difference in cup anteversion angle between THA with and without LIHP (SMD =-0.10, 95\% Cl=-0.61 to $0.41, p=0.70)$. A subgroup analysis also showed that the difference in cup anteversion angle between THA with a previous tantalum rod implanting and control THA group was not significant (SMD =- $0.25,95 \% \mathrm{Cl}=-0.84$ to 0.34 , $p=0.40)$. (Fig5c)

\subsubsection{Cup inclination angle}

Six articles[16, 23, 25, 27-29] provided enough data to assess the cup inclination angle in two groups. There was not significant heterogeneity $\left(I^{2}=0 \%\right)$, therefore the fixed-effects model was used. The pooled outcome estimates of these studies suggested that previous LIHP did not significantly influence the cup inclination angle $(\mathrm{SMD}=0.58,95 \% \mathrm{Cl}=-0.05$ to $1.22, p=0.07)$. The subgroup analysis showed that there was no significant difference in THA with a previous tantalum rod implanting ( $S M D=0.62,95 \% \mathrm{Cl}=-0.13$ to $1.37, p=0.11)$ and $\mathrm{THA}$ with a previous bone grafting or cementing $(\mathrm{SMD}=0.50,95 \% \mathrm{Cl}=-0.67$ to $1.67, p=0.40)$, respectively, compared with the primary THA group. (Fig5d)

\subsubsection{Postoperative HHS}

Eight articles[16, 22, 23, 25-29] reported about the data of postoperative HHS. The fixed-effects model was used because no heterogeneity was observed $\left(R^{2}=40 \%\right)$. The pooled data showed that there was no significant difference in the postoperative HHS between the two groups ( $\mathrm{SMD}=0.01,95 \% \mathrm{Cl}=-0.43$ to $0.46, p=0.96)$. The subgroup analysis showed that there was no significant difference in THA with a previous tantalum rod implanting (SMD=-0.07, 95\% Cl=-0.59 to $0.45, p=0.78)$ and THA with a previous bone grafting or cementing $(\mathrm{SMD}=0.25,95 \% \mathrm{Cl}=-0.62$ to $1.11, p=0.57)$, respectively, compared with the primary THA group. (Fig6)

\subsubsection{Survivorship}

Three articles[16, 22, 28] reported about the rate of revision. In total, three revisions occurred in the prior LIHP group (3/101), while four occurred in the control group (4/190). There was no significant heterogeneity $(R=0 \%)$, 
therefore the fixed-effects model was used. The pooled data showed that there was no significant difference in the survivorship between the two groups (OR=1.38, $95 \% \mathrm{Cl}=0.34$ to $5.55, p=0.65)$. (Fig7)

\subsubsection{Publication bias}

Publication bias was evaluated through visually inspecting the funnel plot of the operative blood loss (Fig8e) and operative time (Fig8f), which indicated that there would be publication bias.

\section{Discussion}

Based on reported in the literature, $59 \%$ of untreated asymptomatic ONFH is unlikely to escape the collapse of femoral head leading to osteoarthritis and destruction of the hip joint[30]. Most of them usually ends up with THA, but the treatments of LIHP are attempted for young patients whenever possible. Due to this, there is a need to better understand the impact of prior LIHP on subsequent THA. In this literature, results showed that the prior LIHP may confer a high risk of subsequent THA surgery, especially the tantalum rod implantation. The prior LIHP increased operative blood loss, operative time, and the rate of intraoperative fracture and stem malalignment. As for clinical outcomes, the difference was not obvious.

In this current meta-analysis, we found that primary THA is better than subsequent THA in terms of operative time and operative blood loss. The effect of LIHP type on subsequent THA was inconsistent in our study. Regarding the THA after previous tantalum rods implantation, several studies reported outcomes compared primary THA. Zuo et al[28] compared 30 THAs performed after the previous tantalum rods implantation and 30 diagnosis-matched THAs without previous tantalum rods, and both the surgery duration and intraoperative blood loss in the tantalum rods implantation group were significantly higher than those in the primary THA group. Similar to their study, several studies[25, 27, 29] also reported that THA after tantalum rods implantation increased blood loss and prolonged operative time compared with primary THA.

The increase in operative time and intraoperative blood loss were related to the process of removing the failed tantalum rods, and the procedure may be difficult due to bone ingrowth in the live bone area of the proximal femur. There are various methods to remove failed tantalum rods. Owens et al[31] described a technical tip for removal of a well-ingrown tantalum rod. Most surgeons are likely to use this standard method to cut the rod at the femoral neck using an oscillating saw, and then a trephine was used to extract the remaining portion in an anterograde way[27, 28]. Some surgeons have also used Kirschner wire or a trephine to drill holes around the tantalum rod in a retrograde method, and the tantalum rod was removed after loosening[24]. Cheng et al[25] attempted both techniques to remove tantalum rods. Different removal methods have different effects on the operative time and intraoperative blood loss, and it could be one of the reasons that caused high heterogeneity in tantalum rod group. No matter which method is used to remove the tantalum rod, surgeons should recognize prolonged surgery duration and large amount of bleeding which may introduce a greater surgical risk, and should take corresponding measures, such as preparing blood products for the transfusion, when performing the THA after failed tantalum rod implantation.

While regarding other LIHP types, such as core decompression with bone grafting or cementing, several studies showed that there was no significant difference in the operative time and intraoperative blood loss between the two groups. Lim et al[16] compared 23 THAs after core decompression with or without cementing and 39 
matched primary THAs, and reported that the operative time and intraoperative blood loss were not significantly different between groups. Furthermore, Zuo et al[28] compared the THA after a bone impaction grafting and the age and gender matched THA reported the similar results. Notably, in their study, they also reported that the surgery duration and operative blood loss were increased in the THA after the tantalum implanting than in the THA after a bone impaction grafting. The reason of this result may be related to the skipped step of removing the grafts.

Intraoperative fracture in the conversion of LIHP to THA would bring difficulties for orthopedic surgeons. In this meta-analysis, there is no statistical difference of the incidence of intraoperative fracture in the two groups. Our results regarding this outcome indicator were also similar to the previous study[15]. However, compared with the previous study $(R R=7.05, P=0.08)$, we found that the trend of the intraoperative fracture rate in the conversion to THA after LIHP was increased in our study $(R R=5.88, P=0.06)$. The reason of this result, as reported by Owens et al[31] and Zuo et al[28] was that, the removal of the tantalum rods or other supporting structures would inevitably impair the integrity of the cancellous bone in the femoral neck. This founding also alerted the surgeon to careful intraoperative manipulation in the conversion to THA.

This meta-analysis showed that the stem malalignment was significantly higher in the THA group after failed LIHP than that in the primary THA group. As one of the hip prostheses implantation, varus or valgus femoral stem may increase the risk of early loosening[32] and insufficiency fractures[33]. The reason of this outcome may be attributable to distortion of the proximal femur and the masked landmark after the LIHP. Based on this, Chu et al[26] cautioned that surgeons would pay attention to the position, angle, depth and strength of femoral toothed mill, and the X-ray machine could be used to judge the position of the femoral stem when necessary.

The position and angle of the acetabular prosthesis, as the frequently used radiographic indices, is one of the essential factors that affects the mid-term and long-term efficacy of THA[34]. The result of this meta-analysis indicates that the cup anteversion angle and cup inclination angle were not significantly different between THA with LIHP and control THA group. However, the subgroup analysis showed that the difference of cup inclination angle between the THA with tantalum rod implantation and control group became more evident, though no statistical difference was found because of limited studies. Whether LIHP influences the cup position and angle needs to be confirmed by further studies.

In terms of the clinical outcomes, the HHS is the most common modality used to assessment long-term clinical results. We found that there did not show significant difference in terms of postoperative HHS between two groups in the eight included articles. Zuo et al[28] also stated that the postoperative HHS was not significantly different between the bone impaction grafting group and tantalum implanting group. As showed in this metaanalysis, the mean postoperative HHS in the included articles were higher than 85, indicating these THA patients were well-functioning. While considering the restriction (such as working on crutches) of hip-preserving surgery to the quality of life, the satisfaction and life quality of these patients were not mentioned though HHS, which could induce inadequate evidence to reflect the subjective feeling of them. Therefore, more clinical trials regarding the subjective feeling of hip-preserving surgery patients are needed in the future.

In this meta-analysis, no difference was observed in the incidence of revision. In most cases, revision surgery is the result of failure THA, which also imposes heavy economic burden on families and societies[35]. Lim et al[16] reported that 1 hip from both previous LIHP group and control group had a periacetabular osteolytic lesion that 
required revision and the revision surgery was performed at 10 and 9 years after the THA in the study and control groups, respectively. Issa et al[22] reported that two patients had undergone revision surgery due to acetabular loosening in the hip joint-preserving group and three revisions for component loosening (two separate revisions for acetabular loosening and one revision for femoral loosening) in primary THA group. In fact, most included studies[24, 25, 27, 29] clearly stated that these were no revision cases during follow-up in both groups. Thus, we believe that previous LIHP is not the risk factor for the following revision.

We acknowledge that this study has several important limitations. First, there might be unfair to evaluate the difference among these different hip-preserving surgery types, but we limited our research object to less invasive hip-preserving surgery and little baseline difference was found. Second, the evidence presented in this study is primarily based on non-RCT reports which are more susceptible to bias, and the limited sample size may also reduce the quality of the evidence. Third, follow-up was of short duration. Without long-term clinical follow-up data (longer than 10 years), it is possible that late complications may have been missed. Fourth, Walter method was used to estimate the SD when the data was not reported, which might influence the conclusions slightly. However, despite these limitations, each of the included studies was of high quality and a subgroup analysis was performed to reduce the heterogeneity when necessary. Overall, the pooled results of this study have a certain clinical guiding significance.

\section{Conclusion}

A total of nine articles met the inclusion and were included in this meta-analysis, results of which showed that prior LIHP increased the difficulty of the conversion to THA, which was mainly reflected in the longer operative time, more intraoperative blood loss and easier intraoperative fracture. Simultaneously, the stem malalignment in the prior LIHP THA group was significantly higher than that in the primary THA group. However, the LIHP does not detrimentally affect the clinical results of subsequent THA, and remains a reliable selection for younger patients.

\section{Declarations}

Acknowledgements: We would like to thank all participants for their cooperation.

Author contribution: Conceptualization: Liang Mo, Yuhao Liu and Wei He. Literature search: Liang Mo, Jianxiong $\mathrm{Li}$, and Zhangzheng Wang. Data extraction and quality assessment: Fayi Huang, Pengfei Xin, Chao Ma, Jiahao zhang, and Haoran Huang. Statistical analysis: Liang Mo and Jianxiong Li. Validation: Chi Zhou and Wei He. Writing: Liang Mo, Jianxiong Li and Yuhao Liu. When there was a disagreement, Liu and He gave advice and guidance. All authors read and approved the final manuscript.

Founding: This research was supported by the National Natural Science Foundation of China (Grant No. 82104883), Natural Science Foundation of Guangdong Province (Grant No. 2021A1515011484), Science Technology Planning Project of Guangzhou (Grant No. 202102020930) and Research Project of Innovating to Strengthen the First Hospital of GZUCM (Grant No. 2019॥I06).

Data availability: Not applicable.

Code availability: Not applicable. 
Ethics approval Our hospital did not require ethical approval for such articles, so this paper did not apply for ethical approval.

Consent to participate Not applicable.

Consent to publish All authors agree to the publication of the article.

Competing interests The authors declare no competing interests.

\section{References}

1. Sultan AA, Mohamed N, Samuel LT, et al. Classification systems of hip osteonecrosis: an updated review. International orthopaedics. 2019;43:1089-1095.

2. Calori GM, Mazza E, Colombo A, Mazzola S, Colombo M. Core decompression and biotechnologies in the treatment of avascular necrosis of the femoral head. EFORT open reviews. 2017;2:41-50.

3. Joint Surgery Group of the Orthopaedic Branch of the Chinese Medical A. Guideline for Diagnostic and Treatment of Osteonecrosis of the Femoral Head. Orthopaedic surgery. 2015;7:200-207.

4. Chughtai M, Piuzzi NS, Khlopas A, Jones LC, Goodman SB, Mont MA. An evidence-based guide to the treatment of osteonecrosis of the femoral head. The bone \& joint journal. 2017;99-B:1267-1279.

5. Hines JT, Jo WL, Cui Q, et al. Osteonecrosis of the Femoral Head: an Updated Review of ARCO on Pathogenesis, Staging and Treatment. J Korean Med Sci. 2021;36:e177.

6. Issa K, Pivec R, Kapadia BH, Banerjee S, Mont MA. Osteonecrosis of the femoral head: the total hip replacement solution. The bone \& joint journal. 2013;95-B:46-50.

7. Swarup I, Shields M, Mayer EN, Hendow CJ, Burket JC, Figgie MP. Outcomes after total hip arthroplasty in young patients with osteonecrosis of the hip. Hip international : the journal of clinical and experimental research on hip pathology and therapy. 2017;27:286-292.

8. Atilla B, Bakircioglu S, Shope AJ, Parvizi J. Joint-preserving procedures for osteonecrosis of the femoral head. EFORT open reviews. 2019;4:647-658.

9. Seyler TM, Marker DR, Ulrich SD, Fatscher T, Mont MA. Nonvascularized bone grafting defers joint arthroplasty in hip osteonecrosis. Clinical orthopaedics and related research. 2008;466:1125-1132.

10. Mont MA, Marulanda GA, Seyler TM, Plate JF, Delanois RE. Core decompression and nonvascularized bone grafting for the treatment of early stage osteonecrosis of the femoral head. Instructional course lectures. 2007;56:213-220.

11. He M, Wei Q, Chen Z, et al. Porous tantalum rod implantation is associated with low survival rates in patients with type $\mathrm{C} 2$ osteonecrosis of the femoral head but has no effect on the clinical outcome of conversion total hip arthroplasty: a retrospective study with an average 8-year follow-up. BMC musculoskeletal disorders. 2020;21:841. 
12. Berend KR, Gunneson E, Urbaniak JR, Vail TP. Hip arthroplasty after failed free vascularized fibular grafting for osteonecrosis in young patients. The Journal of arthroplasty. 2003;18:411-419.

13. Sadile F, Bernasconi A, Russo S, Maffulli N. Core decompression versus other joint preserving treatments for osteonecrosis of the femoral head: a meta-analysis. British medical bulletin. 2016;118:33-49.

14. Auregan JC, Villain B, Begue $T$. What is the rate of patients undergoing a total hip arthroplasty after core decompression and insertion of a tantalum rod in osteonecrosis of the femoral head: a systematic review. International orthopaedics. 2018;42:1631-1638.

15. Deng W, Wang Z, Zhou Y, Shao H, Yang D, Li H. Does prior core decompression have detrimental effect on subsequent total hip arthroplasty for osteonecrosis of the femoral head: A systematic review and meta-analysis. Orthopaedics \& traumatology, surgery \& research : OTSR. 2020;106:1553-1560.

16. Lim SJ, Moon YW, Eun SS, Park YS. Total hip arthroplasty using the S-ROM modular stem after jointpreserving procedures for osteonecrosis of the femoral head. The Journal of arthroplasty. 2008;23:495-501.

17. Shigemura T, Yamamoto $Y$, Murata $Y$, et al. Total hip arthroplasty after failed transtrochanteric rotational osteotomy for osteonecrosis of the femoral head: A systematic review and meta-analysis. Orthopaedics \& traumatology, surgery \& research : OTSR. 2018;104:1163-1170.

18. Shigemura T, Yamamoto Y, Murata Y, Sato T, Tsuchiya R, Wada Y. Total hip arthroplasty after a previous pelvic osteotomy: A systematic review and meta-analysis. Orthopaedics \& traumatology, surgery \& research : OTSR. 2018;104:455-463.

19. Moher D, Liberati A, Tetzlaff J, Altman DG, Group P. Preferred reporting items for systematic reviews and meta-analyses: the PRISMA statement. Journal of clinical epidemiology. 2009;62:1006-1012.

20. Stang A. Critical evaluation of the Newcastle-Ottawa scale for the assessment of the quality of nonrandomized studies in meta-analyses. Eur J Epidemiol. 2010;25:603-605.

21. Walter SD, Yao X. Effect sizes can be calculated for studies reporting ranges for outcome variables in systematic reviews. Journal of clinical epidemiology. 2007;60:849-852.

22. Issa K, Johnson AJ, Naziri Q, Khanuja HS, Delanois RE, Mont MA. Hip osteonecrosis: does prior hip surgery alter outcomes compared to an initial primary total hip arthroplasty? The Journal of arthroplasty. 2014;29:162166.

23. Lee GW, Park KS, Kim DY, Lee YM, Eshnazarov KE, Yoon TR. Results of Total Hip Arthroplasty after Core Decompression with Tantalum Rod for Osteonecrosis of the Femoral Head. Clinics in orthopedic surgery. 2016;8:38-44.

24. Olsen M, Lewis PM, Morrison Z, McKee MD, Waddell JP, Schemitsch EH. Total hip arthroplasty following failure of core decompression and tantalum rod implantation. 2016.

25. Cheng Q, Tang JL, Gu JJ, et al. Total hip arthroplasty following failure of tantalum rod implantation for osteonecrosis of the femoral head with 5- to 10-year follow-up. BMC musculoskeletal disorders. 2018;19:289. 
26. Yaming C, Liang Z, Jinqing Z, Yixin Z. A mid-term follow-up outcomes of total hip arthroplasty in the treatment of patients with non-traumatic avascular necrosis of femoral head failing in core decompression therapy. Chinese Journal of Bone and Joint Surgery. 2018;11:596-599.

27. Ma J, Wang B, Yue D, Sun W, Wang W, Li Z. Outcomes of conversion THA after failed porous tantalum implant for osteonecrosis of the femoral head: a comparative matched study. Hip international : the journal of clinical and experimental research on hip pathology and therapy. 2019;30:703-710.

28. Zuo W, Ma JH, Cui W, Guo WS, Sun W. Comparison of Total Hip Arthroplasty after Two Types of Failed Hip Preserving Procedures with Primary Total Hip Arthroplasty. Orthopaedic surgery. 2020;12:162-169.

29. Ya-ming C, Liang Z, Jin-qing Z, Hong-chao L, Tao B, Yi-xin Z. Total hip arthroplasty following failure of tantalum rod implantation for avascular necrosis of femoral head. Orthopedic Journal of China. 2020;28:21222126.

30. Nam KW, Kim YL, Yoo JJ, Koo KH, Yoon KS, Kim HJ. Fate of untreated asymptomatic osteonecrosis of the femoral head. The Journal of bone and joint surgery. American volume. 2008;90:477-484.

31. Owens JB, Ely EE, Guilliani NM, Suarez JC, Patel PD. Removal of trabecular metal osteonecrosis intervention implant and conversion to primary total hip arthroplasty. The Journal of arthroplasty. 2012;27:12511253.

32. Vresilovic EJ, Hozack WJ, Rothman RH. Radiographic assessment of cementless femoral components. Correlation with intraoperative mechanical stability. The Journal of arthroplasty. 1994;9:137-141.

33. Gill TJ, Sledge JB, Orler R, Ganz R. Lateral insufficiency fractures of the femur caused by osteopenia and varus angulation: a complication of total hip arthroplasty. The Journal of arthroplasty. 1999;14:982-987.

34. Surace MF, Monestier L, D'Angelo F, Bertagnon A. Factors Predisposing to Dislocation After Primary Total Hip Arthroplasty: A Multivariate Analysis of Risk Factors at 7 to 10 Years Follow-up. Surgical technology international. 2016;30:274-278.

35. Weber M, Renkawitz T, Voellner F, et al. Revision Surgery in Total Joint Replacement Is Cost-Intensive. BioMed research international. 2018;2018:8987104.

\section{Tables}

Table.1: The PubMed database literature search strategy 


\begin{tabular}{ll} 
\#1 & Decompression [Title/Abstract] \\
\hline \#2 & Core decompression [Title/Abstract] \\
\hline \#3 & Tantalum implant [Title/Abstract] \\
\hline \#4 & Tantalum rod implantation [Title/Abstract] \\
\hline \#5 & Metal implant [Title/Abstract] \\
\hline \#6 & Trabecular meta implant [Title/Abstract] \\
\hline \#7 & Grafting, Bone [Title/Abstract] \\
\hline \#8 & Bone Grafting [Title/Abstract] \\
\hline \#9 & Transplantation, Bone [Title/Abstract] \\
\hline \#10 & \#1 OR \#2 OR \#3 OR \#4 OR \#5 OR \#6 OR \#7 OR \#8 OR \#9 \\
\hline \#11 & Arthroplasty, Replacement, Hip [Mesh] \\
\hline \#12 & Arthroplasties, Replacement, Hip [Title/Abstract] \\
\hline \#13 & Arthroplasty, Hip Replacement [Title/Abstract] \\
\hline \#14 & Hip Prosthesis Implantation [Title/Abstract] \\
\hline \#15 & Prosthesis Implantation, Hip [Title/Abstract] \\
\hline \#16 & Hip Replacement Arthroplasty [Title/Abstract] \\
\hline$\# 17$ & Arthroplasties, Hip Replacement [Title/Abstract] \\
\hline$\# 18$ & Total Hip Replacement [Title/Abstract] \\
\hline \#19 & Total Hip Arthroplasty [Title/Abstract] \\
\hline \#10 AND \#20 \\
\hline \#11 OR \#12 OR \#13 OR \#14 OR \#15 OR \#16 OR \#17 OR \#18 OR \#19 \\
\hline H1
\end{tabular}

Table.2: The basic characteristics of the included studies. 


\begin{tabular}{|c|c|c|c|c|c|c|}
\hline Authors & Group & $\begin{array}{l}\text { Sample } \\
\text { size(hips) }\end{array}$ & $\begin{array}{l}\text { Gender } \\
(\mathrm{M} / \mathrm{F}))\end{array}$ & BMI & Age $\rrbracket$ years $\rrbracket$ & $\begin{array}{l}\text { Follow-up } \\
\text { 『months } \rrbracket\end{array}$ \\
\hline $\operatorname{Lim}_{S J^{[16]}}$ & $\begin{array}{l}\mathrm{CD} \square \\
\mathrm{CD}+\text { cement }\end{array}$ & 23 & $16 / 7$ & NR & $40 \pm 10$ & $55 \pm 33$ \\
\hline $\begin{array}{l}\text { Primary } \\
\text { THA }\end{array}$ & 39 & $23 / 9$ & NR & $43 \pm 10$ & $57 \pm 34$ & \\
\hline $\begin{array}{l}\text { Issa } \\
K_{\mathbb{Z}}[22]\end{array}$ & $C D$ & 19 & NR & $30(17-45)$ & $45(18-74)$ & $\begin{array}{l}67(32- \\
107)\end{array}$ \\
\hline $\begin{array}{l}\text { Issa } \\
\mathrm{K} \rrbracket^{[22]}\end{array}$ & $\begin{array}{l}\text { CD+bone } \\
\text { grafting }\end{array}$ & 29 & NR & $25(18-44)$ & $38(18-81)$ & $\begin{array}{l}75(13- \\
122)\end{array}$ \\
\hline $\begin{array}{l}\text { Primary } \\
\text { THA }\end{array}$ & 121 & NR & $26(15-42)$ & $41(12-71)$ & $\begin{array}{l}77(38- \\
124)\end{array}$ & \\
\hline $\begin{array}{l}\text { Lee } \\
\text { GW'23] }\end{array}$ & $\begin{array}{l}\text { CD+tantalum } \\
\text { rod }\end{array}$ & 8 & $6 / 0$ & $\begin{array}{l}23.7(20.5- \\
25.6)\end{array}$ & $\begin{array}{l}36.3 \llbracket 32- \\
39)\end{array}$ & $\begin{array}{l}39.8(36- \\
57)\end{array}$ \\
\hline $\begin{array}{l}\text { Primary } \\
\text { THA }\end{array}$ & 16 & $12 / 0$ & $\begin{array}{l}22.8(18.8- \\
27.7)^{-}\end{array}$ & $36.6(32-39)$ & $\begin{array}{l}42.6(38- \\
57)\end{array}$ & \\
\hline Olsen ${ }^{[24]}$ & $\begin{array}{l}C D+\text { tantalum } \\
\text { rod }\end{array}$ & 21 & $12 / 9$ & NR & $37(18-53)$ & $\begin{array}{l}50.4(24- \\
72 \rrbracket^{-}\end{array}$ \\
\hline $\begin{array}{l}\text { Primary } \\
\text { THA }\end{array}$ & 21 & $12 / 9$ & NR & $40(18-58)$ & NR & \\
\hline $\begin{array}{l}\text { Cheng } \\
Q^{[25]}\end{array}$ & $\begin{array}{l}C D+t a n t a l u m \\
\text { rod }\end{array}$ & 39 & $26 / 5$ & $\begin{array}{l}25.2(22.3- \\
26.4)\end{array}$ & $\begin{array}{l}49.3(36- \\
64)\end{array}$ & $\begin{array}{l}88.8(60- \\
120)\end{array}$ \\
\hline $\begin{array}{l}\text { Primary } \\
\text { THA }\end{array}$ & 40 & $26 / 7$ & $\begin{array}{l}24.6(21.5- \\
25.6)\end{array}$ & $43.2(37-64)$ & $\begin{array}{l}88.8(60- \\
120)\end{array}$ & \\
\hline $\begin{array}{l}\text { Chu } \\
\text { YM }^{[26]}\end{array}$ & $\begin{array}{l}\mathrm{CD} \backslash \mathrm{CD}+\text { bone } \\
\text { grafting }\end{array}$ & 27 & $19 / 8$ & $27.9 \pm 4.5$ & $43.7 \pm 14.7$ & $46.4 \pm 9.6$ \\
\hline $\begin{array}{l}\text { Primary } \\
\text { THA }\end{array}$ & 42 & $31 / 11$ & $26.4 \pm 3.7$ & $45.9 \pm 13.3$ & $49.8 \pm 9.2$ & \\
\hline Ma J[27] & $\begin{array}{l}\mathrm{CD} \text { +tantalum } \\
\text { rod }\end{array}$ & 34 & $21 / 11$ & $24.9 \pm 4.2$ & $43.6 \pm 7.6$ & $64.1 \pm 14.7$ \\
\hline $\begin{array}{l}\text { Primary } \\
\text { THA }\end{array}$ & 32 & $16 / 9$ & $25.3 \pm 4.2$ & $44.0 \pm 10.7$ & $59.4 \pm 9.7$ & \\
\hline $\begin{array}{l}\text { Zuo } \\
\text { W』 }\end{array}$ & $\begin{array}{l}\mathrm{CD}+\text { tantalum } \\
\text { rod }\end{array}$ & 30 & NR & $\begin{array}{l}24.05(17.65- \\
31.25)\end{array}$ & $41(21-60 \rrbracket$ & $64(52-88)$ \\
\hline $\begin{array}{l}\text { Zuo } \\
\text { W』 }\end{array}$ & $\begin{array}{l}\mathrm{CD}+\text { bone } \\
\text { grafting }\end{array}$ & 30 & NR & $\begin{array}{l}23.59(18.62- \\
30.25)\end{array}$ & $42(26-65)$ & $59(49-91)$ \\
\hline $\begin{array}{l}\text { Primary } \\
\text { THA }\end{array}$ & 30 & NR & $\begin{array}{l}25.45 \\
(17.94-37.52)\end{array}$ & $41(23-63)$ & $62(54-85)$ & \\
\hline Chu & $\begin{array}{l}\text { CD+tantalum } \\
\text { rod }\end{array}$ & 44 & & $25.92 \pm 3.42$ & $43.7 \pm 14.7$ & $37.91 \pm 7.18$ \\
\hline & & & Page $14 / 21$ & & & \\
\hline
\end{tabular}


$\mathrm{YM}^{[29]}$

Primary

$31 / 11$

$25.24 \pm 3.68$

$45.9 \pm 13.3$

$37.91 \pm 7.18$

THA

CD: core decompression; THA: Total hip arthroplasty; M: male; F: female; NR: not reported; $\mathbb{\text { Q }}$ :different subgroups from a study.

Table.3: Newcastle Ottawa Scale (NOS) for the included studies.

\begin{tabular}{|c|c|c|c|c|c|c|c|c|}
\hline \multirow[t]{2}{*}{ Study } & \multirow{2}{*}{$\begin{array}{l}\text { Year of } \\
\text { publication }\end{array}$} & \multirow{2}{*}{$\begin{array}{l}\text { Year of } \\
\text { surgery }\end{array}$} & \multirow[b]{2}{*}{ Country } & \multirow{2}{*}{$\begin{array}{l}\text { Study } \\
\text { design }\end{array}$} & \multicolumn{3}{|c|}{ NOS } & \multirow[t]{2}{*}{ Score } \\
\hline & & & & & Selection & Comparability & Outcome & \\
\hline $\begin{array}{l}\operatorname{Lim} \\
S J^{[16]}\end{array}$ & 2008 & $\begin{array}{l}1995- \\
2004\end{array}$ & Korea & RCS & $\star \star \star$ & $\star \star$ & $\star \star \star$ & 8 \\
\hline $\begin{array}{l}\text { Issa } \\
\mathrm{K}^{[22]}\end{array}$ & 2014 & $\begin{array}{l}2001- \\
2010\end{array}$ & American & RCS & $\star * *$ & $\star \star$ & $\star \star \star *$ & 8 \\
\hline $\begin{array}{l}\text { Lee } \\
\mathrm{GW}^{[23]}\end{array}$ & 2016 & $\begin{array}{l}2010- \\
2011\end{array}$ & Korea & RCS & $\star \star *$ & $\star \star$ & $\star \star \star$ & 8 \\
\hline Olsen ${ }^{[24]}$ & 2016 & $\begin{array}{l}2002- \\
2013\end{array}$ & Canada & RCS & $\star * *$ & ** & $\star \star \star *$ & 8 \\
\hline $\begin{array}{l}\text { Cheng } \\
\mathrm{Q}^{[25]}\end{array}$ & 2018 & $\begin{array}{l}2007- \\
2012\end{array}$ & China & RCS & $\star \star \star$ & $\star \star$ & $\star \star \star$ & 8 \\
\hline $\begin{array}{l}\text { Chu } \\
\text { YM }^{[26]}\end{array}$ & 2018 & $\begin{array}{l}2013- \\
2015\end{array}$ & China & $\mathrm{RCC}$ & $\star \star$ & ** & $\star \star \star$ & 7 \\
\hline$M a J^{[27]}$ & 2019 & $\begin{array}{l}2009- \\
2014\end{array}$ & China & $\mathrm{RCC}$ & $\star \star \star$ & $\star \star$ & $\star \star \star$ & 8 \\
\hline $\begin{array}{l}\text { Zuo } \\
\mathrm{W}^{[28]}\end{array}$ & 2020 & $\begin{array}{l}2010- \\
2014\end{array}$ & China & $\mathrm{RCC}$ & $\star \star *$ & $\star \star$ & $\star \star \star$ & 8 \\
\hline $\begin{array}{l}\text { Chu } \\
\text { YM }^{[29]}\end{array}$ & 2020 & $\begin{array}{l}2013- \\
2017\end{array}$ & China & RCS & $\star \star *$ & $\star \star$ & $\star \star \star$ & 8 \\
\hline
\end{tabular}

RCC: retrospective case-control study; RCS: retrospective cohort study

Figures 


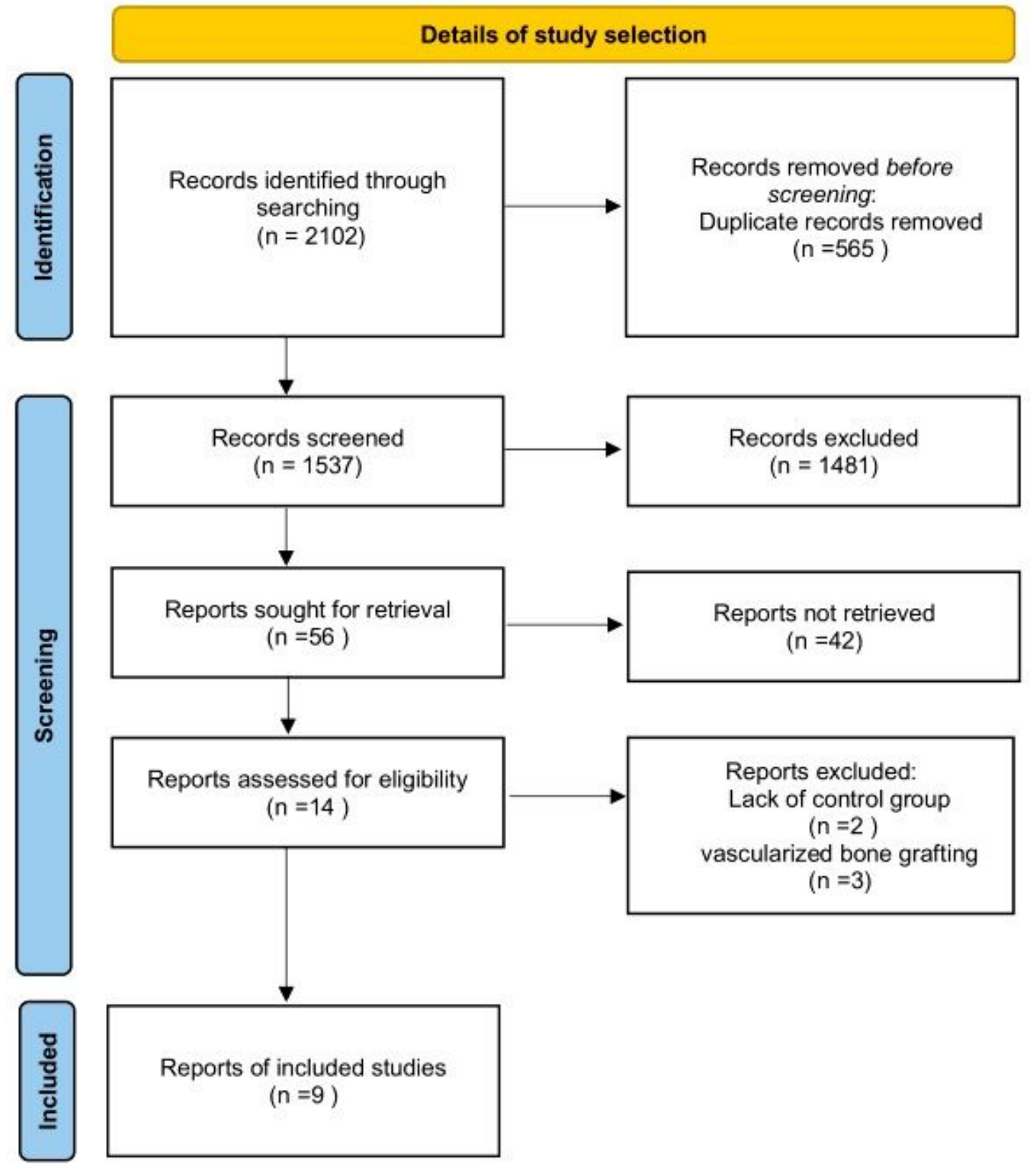

Figure 1

Flowchart of the literature search and study inclusion. 


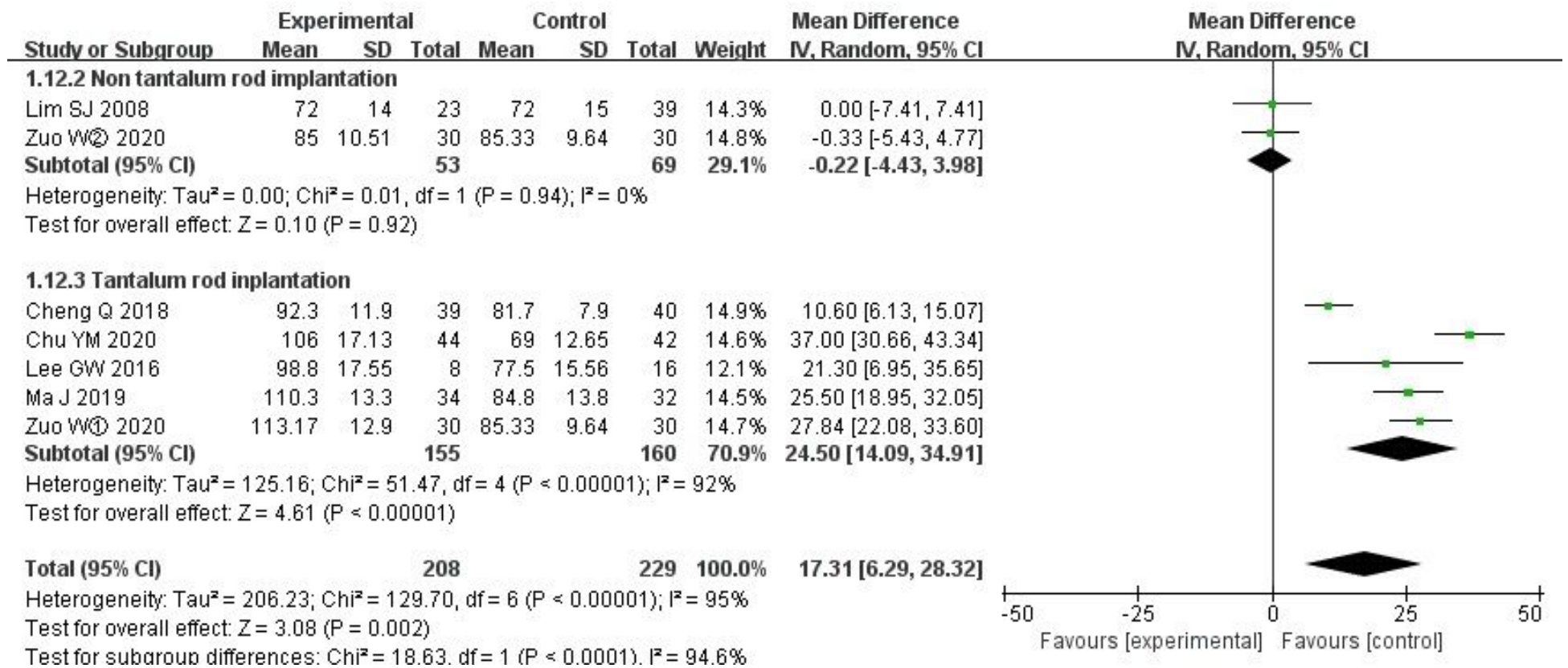

\section{Figure 2}

Operative time - forest plot. IV, inverse variance method; Cl: confidence intervals; df: degrees of freedom; SD: standard deviation.

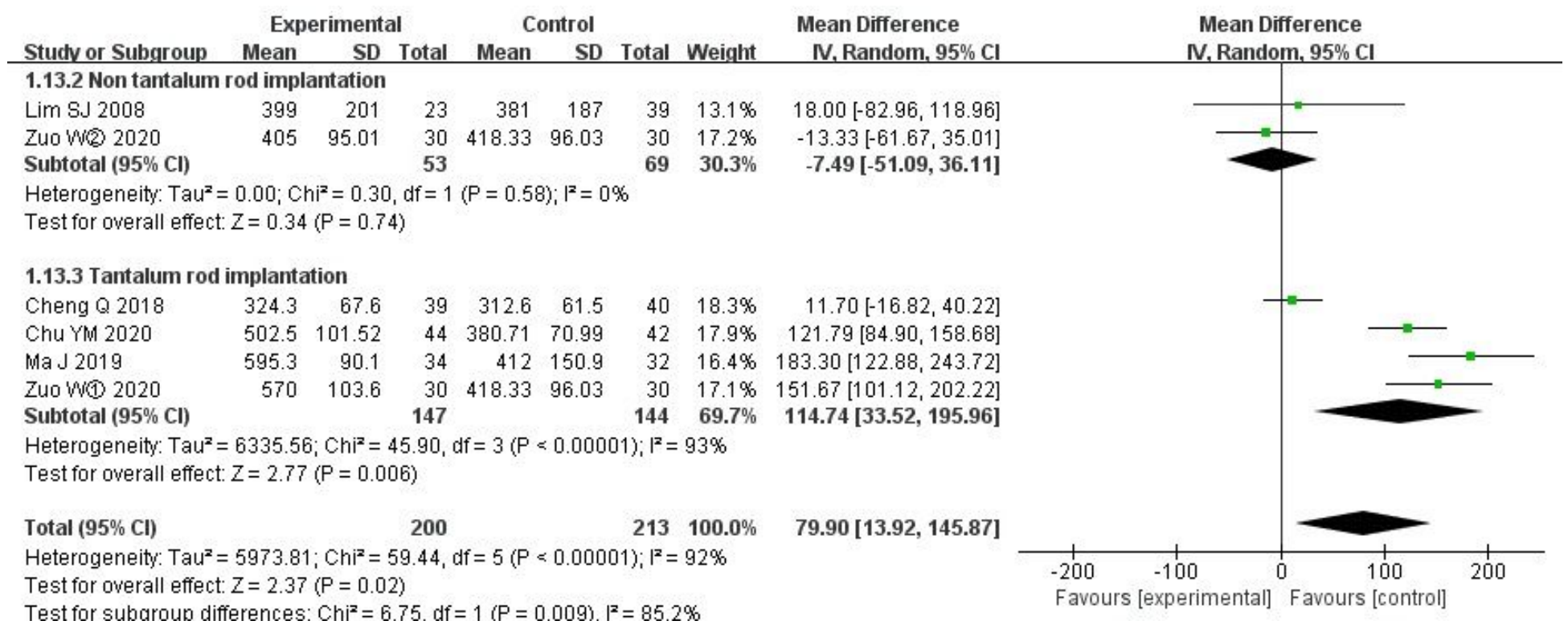

Figure 3

Operative blood loss - forest plot. IV, inverse variance method; Cl: confidence intervals; df: degrees of freedom; SD: standard deviation. 


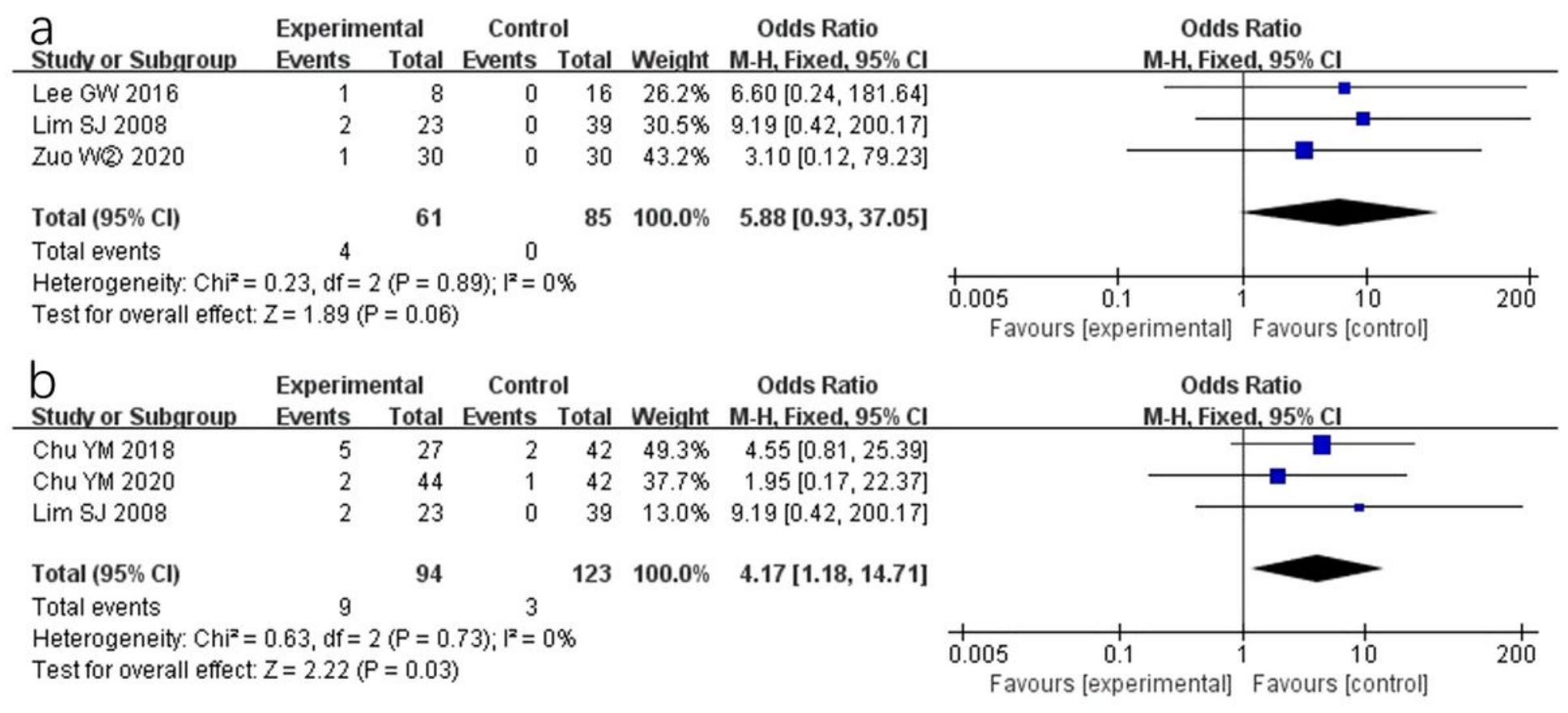

Figure 4

a. Forest plot for intraoperative fracture. b. Forest plot for varus or valgus femoral stem. M-H: Mantel-Haenszel method; Cl: confidence intervals; df: degrees of freedom. IV, inverse variance method; SD: standard deviation. 
C

Experimental Control

Control Mean Difference

Mean Difference

$\begin{array}{lll}\text { Study or Subgroup Mean SD Total Mean SD Total Weight IV. Fixed, } 95 \% \mathrm{Cl} & \text { IV. Fixed, 95\% Cl }\end{array}$

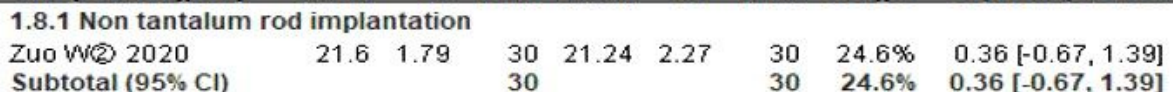

Heterogeneity: Not applicable

Test for overall effect: $Z=0.68(P=0.50)$

1.8.2 Tantalum rod implantation

$\begin{array}{lrr}\text { Cheng Q 2018 } & 18.1 & 3.11 \\ \text { Chu YM 2020 } & 27.25 & 5.61 \\ \text { Lee GW 2016 } & 21.1 & 5.58 \\ \text { Ma J 2019 } & 21.3 & 1.3 \\ \text { Zuo W(1) 2020 } & 21.23 & 1.52 \\ \text { Subtotal (95\% Cl) } & & \end{array}$

Subtotal $(95 \% \mathrm{Cl})$

$\begin{array}{rrrr}30 & 21.24 & 2.27\end{array}$

139

Test for overall effect: $Z=0.84(P=0.40)$

Total $(95 \% \mathrm{Cl})$

169

Heterogeneity $\mathrm{Chi}^{2}=3.55, \mathrm{df}=5(\mathrm{P}=0.62) ; \mathrm{I}^{2}=0 \%$

Test for overall effect: $Z=0.39(P=0.70)$

Test for subaroun differences: $\mathrm{Chi}^{\mathrm{z}}=1.01 . \mathrm{df}=1(\mathrm{P}=0.31) \cdot \mathrm{I}^{\mathrm{z}}=1.3 \%$

$175100.0 \% \quad-0.10[-0.61,0.41]$

$5.9 \% \quad 0.70[-1.42,2.82]$

$4.5 \% \quad 0.47[-1.96,2.90]$

$1.1 \% \quad 0.60[-4.32,5.52]$

$36.5 \%-0.70[-1.55,0.15]$

$27.5 \% \quad-0.01[-0.99,0.97]$

$145 \quad 75.4 \% \quad-0.25[-0.84,0.34]$

Favours [experimental] Favours [control]

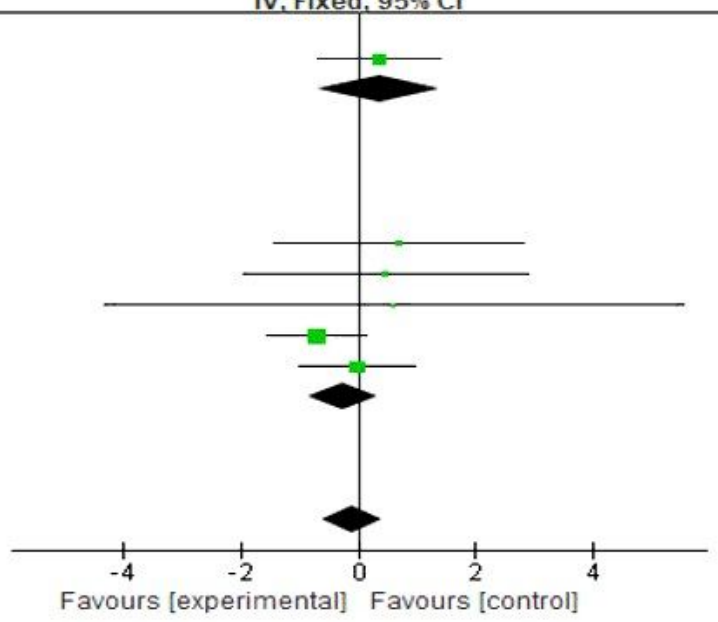

\begin{tabular}{|c|c|c|c|c|c|c|c|c|}
\hline \multirow{2}{*}{$\mathrm{d}_{\text {Study or Subgroup }}$} & \multicolumn{3}{|c|}{ Experimental } & \multicolumn{3}{|c|}{ Control } & \multicolumn{2}{|r|}{ Mean Difference } \\
\hline & Mean & SD & Total & Mean & SD & Total & Weight & IV, Fixed, $95 \% \mathrm{Cl}$ \\
\hline \multicolumn{9}{|c|}{ 1.7.2 Non tantalum rod implantation } \\
\hline Lim SJ 2008 & 40 & 6 & 23 & 40 & 5 & 39 & $4.7 \%$ & 0. \\
\hline Zuo W@2020 & 41 & 2.7 & 34 & 40.4 & 2.6 & 32 & $24.5 \%$ & 0.6 \\
\hline Subtotal $(95 \% \mathrm{Cl})$ & & & 57 & & & 71 & $29.2 \%$ & $0.50[-0.67,1.67]$ \\
\hline
\end{tabular}

Subtotal $(95 \% \mathrm{Cl})$

57

Heterogeneity: Chi $^{2}=0.14, d f=1(P=0.71) ;\left.\right|^{2}=0 \%$

Test for overall effect: $Z=0.84(P=0.40)$

1.7.3 Tantalum rod implantation

$\begin{array}{lrrrrrrrr}\text { Cheng Q 2018 } & 38.6 & 3.11 & 23 & 37.8 & 3.05 & 25 & 13.1 \% & 0.80[-0.94,2.54] \\ \text { Chu YM 2020 } & 40.11 & 4.43 & 44 & 38.88 & 3.78 & 42 & 13.2 \% & 1.23[-0.51,2.97] \\ \text { Lee GW 2016 } & 39.9 & 3.96 & 8 & 39 & 4.67 & 16 & 3.1 \% & 0.90[-2.67,4.47] \\ \text { Ma J 2019 } & 41 & 2.7 & 34 & 40.4 & 2.6 & 32 & 24.5 \% & 0.60[-0.68,1.88] \\ \text { Zuo W(1) 2020 } & 41.16 & 3.44 & 30 & 41.19 & 2.6 & 30 & 16.8 \% & -0.03[-1.57,1.51] \\ \text { Subtotal (95\% Cl) } & & & 139 & & & 145 & 70.8 \% & 0.62[-0.13,1.37]\end{array}$

Heterogeneity: $\mathrm{Chi}^{2}=1.22, \mathrm{df}=4(\mathrm{P}=0.87) ; \mathrm{I}^{2}=0 \%$

Test for overall effect: $Z=1.61(P=0.11)$

Total $(95 \% \mathrm{CI}) \quad 196$

$216100.0 \% \quad 0.58[-0.05,1.22]$

Heterogeneity: $\mathrm{Chi}^{2}=1.38, \mathrm{df}=6(\mathrm{P}=0.97) ; \mathrm{I}^{2}=0 \%$

Test for overall effect: $Z=1.81(P=0.07)$

Test for subaroun differences: $\mathrm{Chi}^{2}=0.03 . \mathrm{df}=1(\mathrm{P}=0.87) . \mathrm{I}^{2}=0 \%$

\section{Figure 5}

c. Forest plot for Cup anteversion angle. d. Forest plot for Cup inclination angle. IV, inverse variance method; Cl: confidence intervals; df: degrees of freedom; SD: standard deviation. 


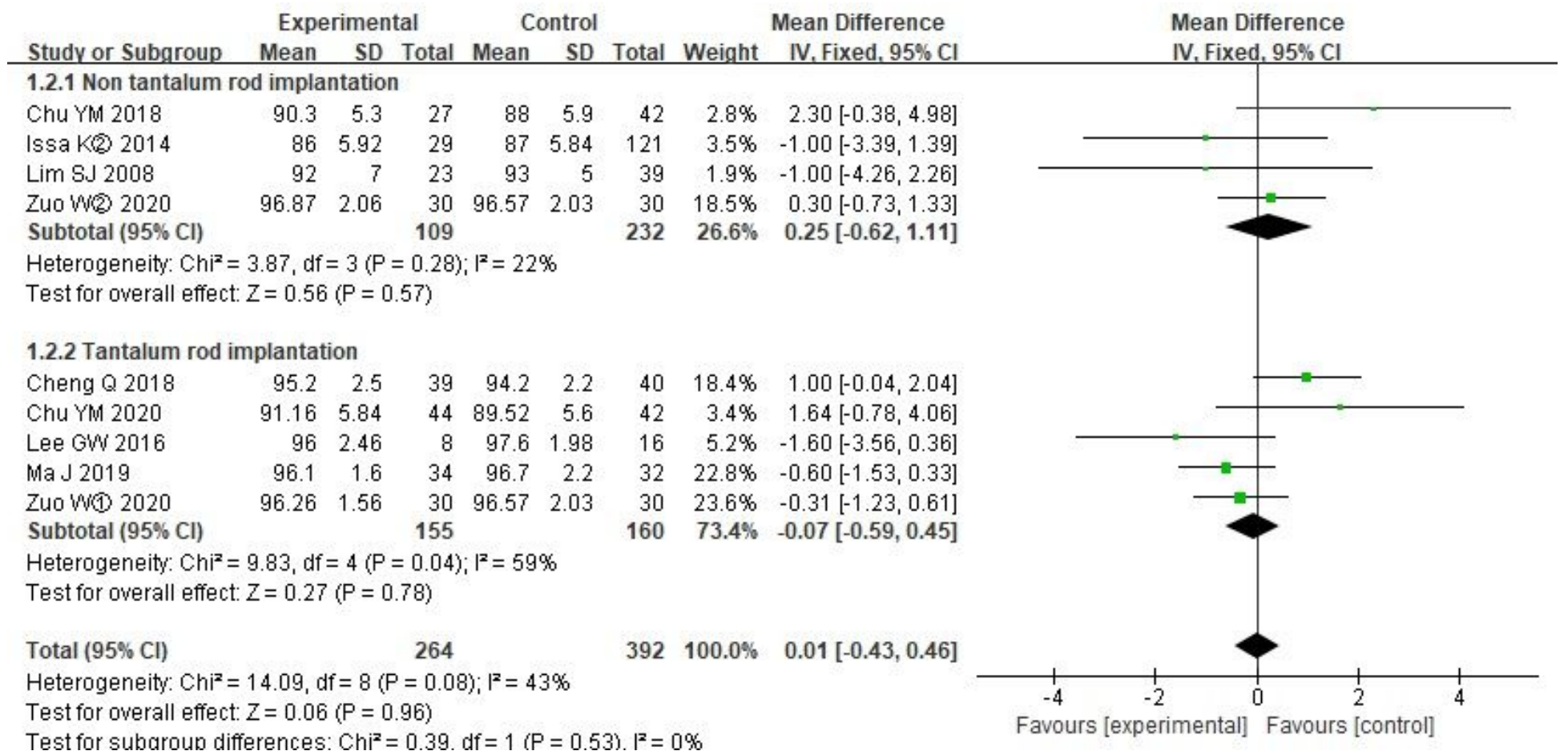

\section{Figure 6}

Postoperative HHS at the final follow-up- forest plot. IV, inverse variance method; Cl: confidence intervals; df: degrees of freedom; SD: standard deviation.

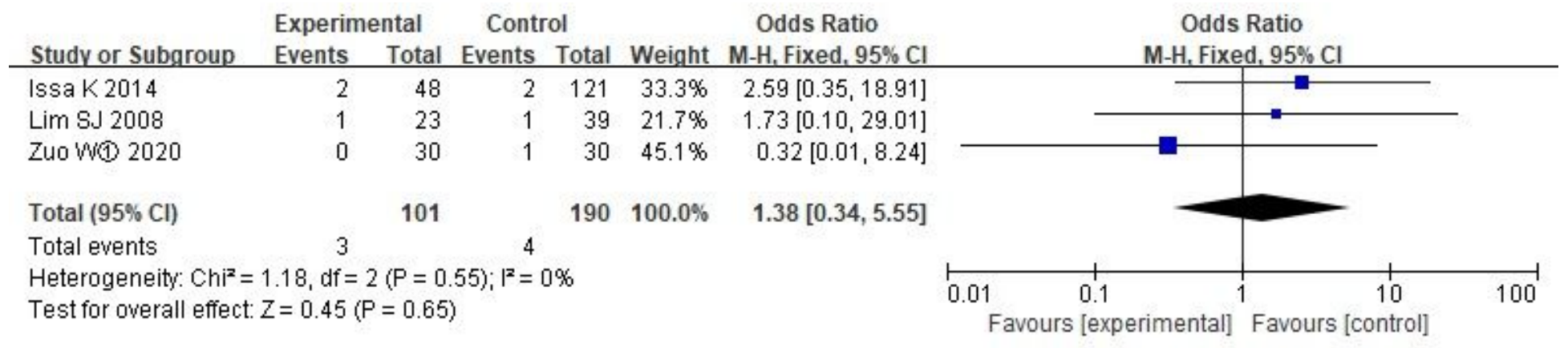

\section{Figure 7}

a. Survivorship-forest plot. M-H: Mantel-Haenszel method; Cl: confidence intervals; df: degrees of freedom. IV, inverse variance method; SD: standard deviation. 

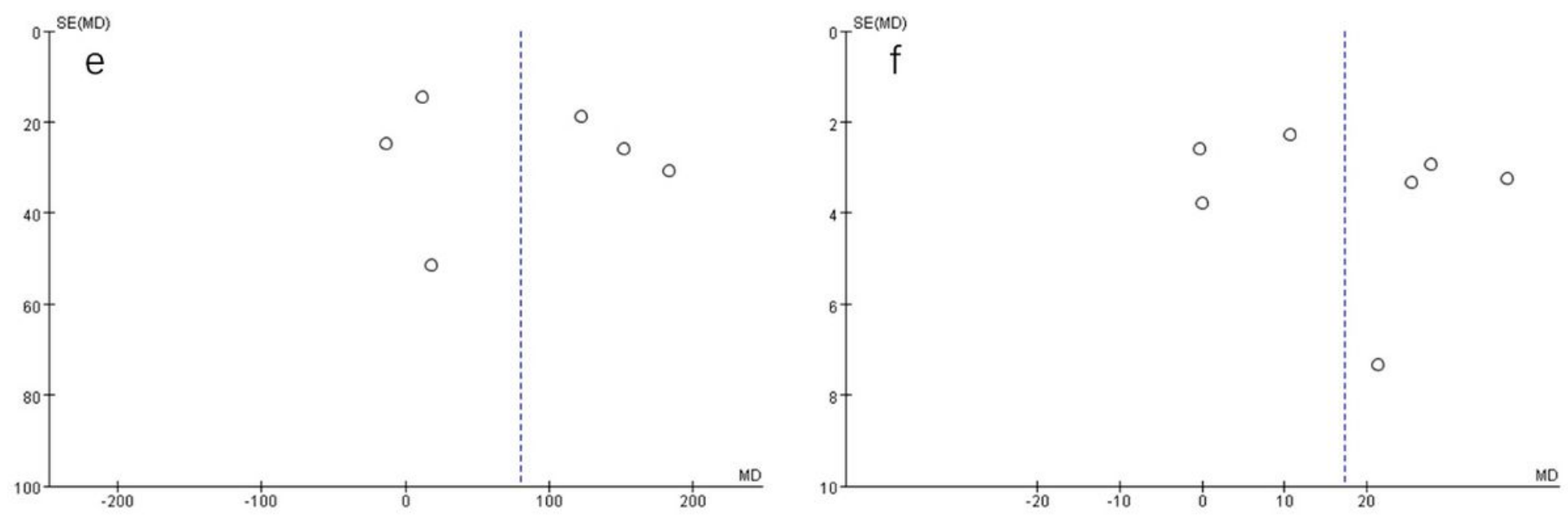

\section{Figure 8}

e. Funnel plot for operative blood loss. f. Funnel plot for operative time. An asymmetry was exhibited in the funnel plot, which reflected the publication bias. 